\title{
Quantitative APT analysis of Ti(C,N)
}

\author{
J. Angseryd ${ }^{1,2}$, F. Liu ${ }^{2}$, H.-O. Andrén ${ }^{2}$, S.S.A. Gerstl ${ }^{3}$ and M. Thuvander ${ }^{2}$
}

\author{
1- R\&D Sandvik Tooling, SE-126 80 Stockholm, Sweden \\ (* jenny.angseryd@sandvik.com, +4687266632$)$ \\ 2- Department of Applied Physics, Microscopy and Microanalysis group, Chalmers University of Technology, SE-412 96 Gothenburg, Sweden \\ (* jenny.angseryd@chalmers.se; fang.liu@chalmers.se; andren@chalmers.se and mattias.thuvander@chalmers.se) \\ 3- Imago Scientific Instruments, Madison, WI 53711 USA
}

\begin{abstract}
A specially produced $\mathrm{Ti}(\mathrm{C}, \mathrm{N})$ standard material, with a known nominal composition, was investigated with laser assisted atom probe tomography. The occurrence of molecular ions and single/multiple events was found to be influenced by the laser pulse energy, and especially $\mathrm{C}$ related events were affected. Primarily two issues were considered when the composition of $\operatorname{Ti}(\mathrm{C}, \mathrm{N})$ was determined. The first is connected to detector efficiency, due to the detector dead-time. The second is connected to peak overlap in the mass spectrum. A method is proposed for quantification of the $\mathrm{C}$ content in order to establish the $\mathrm{C} / \mathrm{N}$ ratio. A correction was made to the major $\mathrm{C}$ peaks, $\mathrm{C}$ at 6 and $12 \mathrm{Da}$, with the ${ }^{13} \mathrm{C}$ isotopes, at 6.5 and $13 \mathrm{Da}$, according to the known natural abundance. In addition, a correction of the peak at $24 \mathrm{Da}$, where $\mathrm{C}$ and $\mathrm{Ti}$ overlap, is proposed based on the occurrence of single/multiple events for respective element. The results were compared to results from other techniques such as electron energy loss spectroscopy, chemical analysis and X-ray diffraction. After applying the corrections, atom probe tomography results were satisfactory. Furthermore, the content of dissolved $\mathrm{O}$ in $\mathrm{Ti}(\mathrm{C}, \mathrm{N})$ was successfully quantified.
\end{abstract}

Keywords: Atom probe tomography, APT, Ti(C,N), quantification, PCBN

\section{Introduction}

The new generation of atom probe tomography (APT) instruments, with a laser pulsing option in addition to voltage pulsing, has enabled a wider range of materials to be investigated [1]. With voltage pulsing, materials suitable for analyses were limited to good electrically conducting materials such as metals. Titanium carbo nitride $(\mathrm{Ti}(\mathrm{C}, \mathrm{N}))$ is an interesting phase found in many materials, most notably in cutting tool materials. In cermets $\operatorname{Ti}(\mathrm{C}, \mathrm{N})$ is one of the hard phases which are embedded in a soft metal binder phase, whereas it is a matrix phase contributing to ductility in the very hard polycrystalline cubic boron nitride (PCBN) materials. Cermets have previously been studied using voltagepulsed atom probe [2-9]. Now it has also become possible to analyse $\mathrm{Ti}(\mathrm{C}, \mathrm{N})$ containing materials such as PCBN materials consisting of $\sim 55 \mathrm{vol} \%$ non-conductive $\mathrm{cBN}$ grains, with the microstructure described in previous papers [1011]. In order to determine the composition of the various phases in PCBN materials with APT, an optimisation of the quantification procedure turned out to be necessary for each phase. For this reason a Ti(C,N) standard material was produced with a similar high-pressure and high-temperature (HPHT) sintering process as for PCBN materials.

This paper is focused on quantitative analysis of this $\operatorname{Ti}(\mathrm{C}, \mathrm{N})$ standard material with APT. It is of great interest to accurately quantify the $\mathrm{C}$ and $\mathrm{N}$ contents in different grains as well as any dissolved amount of O. Even though Ti(C,N) only consists of three elements, four with $\mathrm{O}$, some difficulties arose when $\mathrm{Ti}(\mathrm{C}, \mathrm{N})$ was analysed with APT, as well as with other techniques. The varying grain size, with grains ranging down to nanometre sizes, is limiting for many characterisation techniques. For electron microscopy methods, specimen contamination affects quantification of C. Closely positioned and overlapping peaks occur in energy dispersive X-ray (EDX) analyses with peak overlap of Ti and $\mathrm{N}$. In the case of electron energy-loss spectroscopy (EELS) the N, Ti and O edges are closely positioned. Thin film specimens often suffer from surface oxidation [11], which will have consequences on quantitative analysis of phases that only contain small amounts of oxygen, such as the $\operatorname{Ti}(\mathrm{C}, \mathrm{N})$ phase of interest here.

In this study, the influence of the applied laser pulse energy on the analyses was investigated. Evaluation of the Ti(C,N) mass spectrum showed that different elements had different tendencies to field-evaporate as single or multiple events (more than one detected ion per pulse). Variations in laser energy affected the occurrence of multiple events, as well as the amount of molecular ions. Since all detectors used in APT instruments suffer from a dead-time which affects the detection efficiency, losses in major peaks such as ${ }^{12} \mathrm{C}^{2+}$ and ${ }^{12} \mathrm{C}^{+}$were expected [12-13]. In this paper an efficient correction for these losses [12] is applied and a method to correct for the $\mathrm{Ti}^{2+}$ and $\mathrm{C}_{2}{ }^{+}$overlap at $24 \mathrm{Da}$ in quantification calculations is presented. Finally, APT analysis as a quantitative tool was compared with other techniques such as EELS, X-ray diffraction (XRD) and chemical analysis.

\section{Material}

The investigated material was a sintered $\mathrm{Ti}(\mathrm{C}, \mathrm{N})$ material produced from a powder with nominal composition $\operatorname{Ti}\left(\mathrm{C}_{0.7} \mathrm{~N}_{0.3}\right)$ and $2 \mu \mathrm{m}$ grain size. It was pressed and sintered in a similar HPHT manufacturing procedure as PCBN 
materials, typically $1500{ }^{\circ} \mathrm{C}$ and $5 \mathrm{GPa}$. Small amounts of oxygen appeared in the Ti(C,N) as a result of the high affinity of $\mathrm{Ti}$ to $\mathrm{O}$. Oxygen is present as surface oxides on the $\mathrm{Ti}(\mathrm{C}, \mathrm{N})$ powder, which are difficult to reduce and completely remove before the sintering process. Hence, this led to small amounts of $\mathrm{O}$ dissolved in the $\mathrm{Ti}(\mathrm{C}, \mathrm{N})$ phase.

\section{Experimental techniques}

The sintered $\operatorname{Ti}(\mathrm{C}, \mathrm{N})$ material was primarily investigated with APT. The results were then compared to analyses made with EELS, XRD and chemical analysis. The EELS investigations were carried out on an FEI TEM Tecnai F30 ST with a Gatan energy filter GIF2002. A TEM specimen was prepared in a dual beam focused ion beam scanning electron microscope (FIB/SEM). The TEM was operated at $300 \mathrm{kV}$. A dispersion of $0.5 \mathrm{eV} /$ channel was used together with a collection semi-angle of $5.2 \mathrm{mrad}$ and a convergence semi-angle of $3.5 \mathrm{mrad}$.

XRD was performed on polished samples. A reference material of WC was used to calibrate the XRD spectra. The measurements were done using a Bruker D8 Discover-GADDS X-ray diffractometer (CuKa radiation). Chemical analysis was performed with $\mathrm{LECO}^{\mathrm{TM}}$ systems for $\mathrm{C}, \mathrm{N}$ and $\mathrm{O}$. The $\mathrm{C}$ content was determined with an induction furnace that measures carbon by infrared (IR) absorption. The $\mathrm{N}$ and $\mathrm{O}$ contents were measured with the inert gas fusion principle with He. Thermal conductivity was used as detection method for N and IR was used for O. The Ti content was measured with X-ray fluorescence spectrometry.

Atom probe specimens were produced by an in-situ lift out technique in a dual beam FIB/SEM. The triangular prism "Toblerone" technique, described by Miller and Russell [14], was used to produce multiple atom probe specimens positioned on prefabricated silicon posts. An Imago LEAP 3000X HR local electrode APT instrument was used for analysis and laser pulsing (wavelength $532 \mathrm{~nm}$ ) was utilised. Data analysis was performed with the IVAS ${ }^{\mathrm{TM}} 3.4 .1$ software using a bin width of 1/1000 Da. For decomposition calculations the background was removed using the builtin routine in the IVAS software. For correction calculations based on the natural abundance of isotopes, the background was removed by taking away the average background signal from two windows of equal width as the peak of interest, positioned before and after the peak. All analyses were made with an evaporation rate of $0.2 \%$ detected ions per pulse, a temperature of 50-65 K and a pulse frequency of $200 \mathrm{kHz}$. The laser pulse energy was varied in the range 0.2 to $0.6 \mathrm{~nJ}$.

\section{Results and discussion}

\subsection{TEM EELS, XRD and chemical analysis}

EELS data were collected as several point spectra in thin areas $(\mathrm{t} / \lambda<0.4$, where $\lambda$ is the electron mean free path in the phase) from a $\mathrm{Ti}(\mathrm{C}, \mathrm{N})$ thin foil specimen. The mean value of these point analyses provided the following $\mathrm{C} / \mathrm{N}$ ratio: $C / N$ $=33.4 / 15.1[\mathrm{at} \%]=2.21$. The $\mathrm{O}$ amount in these EELS calculations was as high as $\sim 11$ at $\%$, which was mainly a result of surface oxides formed on the thin TEM specimen [11]. The XRD diffractogram showed peaks corresponding to $\operatorname{Ti}\left(\mathrm{C}_{0.7}, \mathrm{~N}_{0.3}\right)$. The measured lattice parameter $4.2984(1) \AA$ corresponds to a $\mathrm{C} / \mathrm{N}$ ratio of 2.23 , assuming stoichiometry and neglecting the effect of any dissolved oxygen. The chemical analysis of the $\mathrm{Ti}(\mathrm{C}, \mathrm{N})$ material provided a $\mathrm{C} / \mathrm{N}$ ratio of $C / N=33.1 / 15.9[a t \%]=2.08$ and the $\mathrm{O}$ content obtained was 1.16 at $\%$.

\subsection{Effect of laser energy on APT spectra}

In APT analysis of the $\mathrm{Ti}(\mathrm{C}, \mathrm{N})$ material, various laser energies were applied to study their influence on the mass spectrum. Four different laser energies were used; $0.2,0.3,0.4$ and $0.6 \mathrm{~nJ}$. The charge state ratios of ${ }^{48} \mathrm{Ti}^{3+} /{ }^{48} \mathrm{Ti}^{2+}$ were: $0.39,0.26,0.23$ and 0.16 , respectively. An example of a complete mass spectrum taken from the analysis with $0.2 \mathrm{~nJ}$ is presented in figure 1. The number of molecular ions in the mass spectrum increased with increasing laser energy, see table 1. This can be illustrated by focusing on $\mathrm{C}$ containing peaks. Figure 2 illustrates the occurrence of $\mathrm{C}$ as either atomic ions $\left(\mathrm{C}^{+}\right.$at 12 and $13 \mathrm{Da}$ or $\mathrm{C}^{2+}$ at 6 and $\left.6.5 \mathrm{Da}\right)$ or as molecular ions $\left(\mathrm{C}_{\mathrm{Mol}}\right.$ given as at $\% \mathrm{C}$ from $\mathrm{C}$ containing molecular ions) as a function of laser energy. The amount of $\mathrm{C}$ as atomic ions decreased with increasing laser energy and the amount of $\mathrm{C}$ in molecular ions consequently increased. $\mathrm{C}$ containing molecular ions were present as for example $\mathrm{C}_{3}{ }^{+}, \mathrm{C}_{3}{ }^{2+}, \mathrm{C}_{4}{ }^{+}$and $\mathrm{C}_{5}{ }^{+}$. The distribution of these also varied with laser energy (table 1). The large molecular ions $\mathrm{C}_{6}{ }^{+}$and $\mathrm{C}_{7}^{+}$were only seen in very small amounts when running with the highest laser energy, i.e. $0.6 \mathrm{~nJ}$.

When $\mathrm{N}$ was present as molecular ions a similar dependence with laser energy as for $\mathrm{C}$ was seen; more of the $\mathrm{N}$ content was found as molecular ions $\left(\mathrm{N}_{\mathrm{Mol}}\right)$ with increasing laser energy as figure 3 and table 1 show. There was a decrease in the amount of singly charged $\mathrm{N}\left({ }^{14} \mathrm{~N}^{+}\right.$at $\left.14 \mathrm{Da}\right)$ with increasing laser energy, whereas the amount of doubly charged $\mathrm{N}$ $\left({ }^{14} \mathrm{~N}^{2+}\right.$ at $\left.7 \mathrm{Da}\right)$ behaved differently and remained relatively constant.

\subsubsection{Single and multiple events as a function of laser energy}

With the IVAS software, separate spectra from single events and multiple events may be constructed. It was found that fraction of multiple events decreased with increasing laser energy. Another observation made was that the appearance of single and multiple events in the individual ${ }^{12} \mathrm{C}^{2+}$ and ${ }^{12} \mathrm{C}^{+}$peaks, as well as in the peaks at 16 and $24 \mathrm{Da}\left(\mathrm{Ti}^{3+} / \mathrm{O}^{+}\right.$at 16 $\mathrm{Da}$ and $\mathrm{Ti}^{2+} / \mathrm{C}^{2+}$ possibly $\mathrm{C}_{4}{ }^{2+}$ at $24 \mathrm{Da}$ ), was influenced differently by laser energy variations. For a laser energy of 0.2 $\mathrm{nJ}$, the ${ }^{12} \mathrm{C}^{+}$peak had about twice as many multiple events as single events and the ${ }^{12} \mathrm{C}^{2+}$ peak had more than three times as many multiple events. The peak at $24 \mathrm{Da}$ had $\sim 30 \%$ less multiple events than single events (at $0.2 \mathrm{~nJ}$ ), whereas the 
peak at $16 \mathrm{Da}$ contained up to twice as many multiple events as single events. At a laser energy of $0.6 \mathrm{~nJ}$, the ${ }^{12} \mathrm{C}^{+}$peak had around three times more multiple events than single events, while the ${ }^{12} \mathrm{C}^{2+}$ peak only had roughly twice the amount of multiple events compared to single events. The peak at $24 \mathrm{Da}$, on the other hand, consisted of up to three times more single events than multiple events whilst the peak at 16 Da contained $\sim 50 \%$ more multiple events.

If the peaks at 16 and $24 \mathrm{Da}$ were separated into single and multiple event peaks, a difference in peak shape was observed, see figure 4 and 5. It was apparent that the multiple event and single event peak profiles at 16 Da coincided well, i.e. they exhibited the same shape. At $24 \mathrm{Da}$, on the other hand, the multiple event peak was wider than the single event peak. The variation of the peak width may be connected to the overlap of two types of ions, ${ }^{48} \mathrm{Ti}^{2+}$ and $\mathrm{C}_{2}{ }^{+}$, at 24 Da. The tendency of $\mathrm{C}_{2}{ }^{+}$to rather be detected as multiple events and the fact that it has a slightly higher mass-to-charge ratio than ${ }^{48} \mathrm{Ti}^{2+}$ may cause the broadening of the multiple event peak. The full width half maximum (FWHM) was 355 for the multiple event peak and 465 for the single event peak $(0.2 \mathrm{~nJ})$. These studies also showed that the ratio between the ${ }^{46} \mathrm{Ti}^{2+}$ and ${ }^{47} \mathrm{Ti}^{2+}$ peaks and the peak at $24 \mathrm{Da}$ was different in the single event and multiple event spectra, see figure 4 and 5. In the multiple event peak at $24 \mathrm{Da}$ a considerable part was missing, which will be further addressed in section 4.3 .

\subsubsection{Interpretation of findings}

Since a constant evaporation rate was used in all experiments, increased pulse energy meant a lower evaporation field. Thus, there was a simultaneous variation in field and temperature between the experiments. It appears that the occurrence of molecular ions most likely depended on temperature. An increased temperature resulted in both more and larger molecular ions. The charge state of a specific ion is known to depend on the field, in accordance with the post-ionisation theory [15]. However, in the case of $\mathrm{C}$ the situation becomes complicated by the presence of molecular ions. It appears that a specific molecular ion can only have a certain highest charge state. For example, $\mathrm{C}_{3}$ was observed as singly and doubly charged but never as triply charged. If the field is so high that $\mathrm{a}_{3}{ }^{3+}$ ion is field evaporated, it will probably immediately dissociate into $\mathrm{C}^{2+}$ and $\mathrm{C}_{2}^{+}$(or three $\mathrm{C}^{+}$), before acceleration commences. Likewise, the ion $\mathrm{C}_{2}{ }^{3+}$ was never observed; such an ion would split into $\mathrm{C}^{+}$and $\mathrm{C}^{2+}$. If this dissociation occurs after the acceleration is completed, $\mathrm{C}^{2+}$ will get a too low energy and $\mathrm{C}^{+}$a too high energy. In a voltage pulsed atom probe without energy compensation we occasionally observed pairs of such $\mathrm{C}$ atoms in the past (a late $6 \mathrm{Da}$ and an early $12 \mathrm{Da}$ from the same pulse). However, energy compensation will move such ions to their correct positions. Consequently, less molecular ions and more multiple events may be expected at a higher field, i.e. at lower pulse energy. The fact that molecular ions may dissociate means that the charge state distribution of $\mathrm{C}^{+}$and $\mathrm{C}^{2+}$ is affected both by field dependent post-ionisation of $\mathrm{C}^{+}$and by dissociation of molecular species. Therefore it does not vary with field in a regular fashion. The same reasoning can of course be applied to nitrogen.

\subsection{APT quantification of $\mathrm{Ti}(\mathrm{C}, \mathrm{N})$}

Although the investigated phase is simple, quantifying the composition was found to be extremely demanding. First of all, the three elements $\mathrm{Ti}, \mathrm{C}$ and $\mathrm{N}$ have a tendency to combine and form various molecular ions, as discussed in section 4.2 and shown in table 1. Secondly, around half of the detector events were multiple events, a circumstance that affects quantification because of the dead-time of the detector. The laser energy will have an impact on the fraction of multiple events (typically the fraction will increase with decreasing laser energy). In this section, two correction methods will be applied in order to improve the quantification. The chemical composition obtained after peak decomposition is shown in table 2 together with results after applying the corrections. The first method targets the ${ }^{12} \mathrm{C}^{2+}$ and ${ }^{12} \mathrm{C}^{+}$peaks, while the second method focuses on the overlap between the ${ }^{12} \mathrm{C}_{2}^{+}$and ${ }^{48} \mathrm{Ti}^{2+}$ at $24 \mathrm{Da}$.

\subsubsection{Correction of ${ }^{12} \mathrm{C}^{2+}$ and ${ }^{12} \mathrm{C}^{+}$by ${ }^{13} \mathrm{C}^{2+}$ and ${ }^{13} \mathrm{C}^{+}$}

Adjacent $\mathrm{C}$ atoms have a tendency to field evaporate during the same pulse, causing them to arrive at the detector close in time and space. If they have the same mass-to-charge ratio, the risk will be high that they are recorded as a single ion leading to preferential losses in certain peaks. Indeed, it was observed that the ratios of ${ }^{12} \mathrm{C}^{2+} /{ }^{13} \mathrm{C}^{2+}$ and ${ }^{12} \mathrm{C}^{+} /{ }^{13} \mathrm{C}^{+}$were always significantly smaller than expected from the natural abundance. A mass spectrum with a close up of the $\mathrm{C}^{2+}$ and $\mathrm{C}^{+}$peaks can be found in figure 6 . The probability to detect two ${ }^{12} \mathrm{C}$ from the same pulse is more than 8000 times higher than the probability to detect two ${ }^{13} \mathrm{C}$. Hence, the ${ }^{13} \mathrm{C}^{\mathrm{n}+}$ peaks are virtually unaffected by the detector dead-time, while significant losses of ${ }^{12} \mathrm{C}^{\mathrm{n}}$ are expected. As a result, a correction $\left({ }^{13} \mathrm{C}\right.$ correction) based on the concentration of ${ }^{13} \mathrm{C}^{\mathrm{n}+}$ described by Thuvander et al. [12] was used. Therefore, the concentration of ${ }^{12} \mathrm{C}^{\mathrm{n}+}$, was thus obtained by multiplying the measured ${ }^{13} \mathrm{C}^{\mathrm{n}+}$ peaks by $92.5 \pm 7.6$ (the natural abundance of ${ }^{13} \mathrm{C}$ is $1.07 \pm 0.08 \%$, according to Böhlke et al. [16]). The chemical composition obtained after the ${ }^{13} \mathrm{C}$ correction is closer to the expected composition, see table 2 . The correction $\left(\mathrm{C}_{\text {Corr }}\right)$ decreases with increasing laser energy, see figure 3 , because of the small amount of atomic $\mathrm{C}$ ions and the high amount of $\mathrm{C}$ in molecular ions. Since the statistical counting error is proportional to $1 / \sqrt{ } \mathrm{N}$, having the analyses based on a peak that is $\sim 1 \%$ of the main peak gives a $\sim 10$ times larger counting uncertainty. Thus, for phase analysis the uncertainty can be rather low if the data set contains a few million atoms. However, in addition to the counting error there is an uncertainty due to the variation in ${ }^{13} \mathrm{C}$ abundance in different terrestrial sources, which is rather large. Thus, in many cases this uncertainty dominates over the counting error. 


\subsubsection{Correction method for the 24 Da peak}

Attempts to use an isotope correction on $\mathrm{Ti}^{2+}$ at $24 \mathrm{Da}$ were made with the isotopes at 24.5 and $25 \mathrm{Da}$ in order to discover any contributions by overlap from $\mathrm{C}_{2}{ }^{+}$or $\mathrm{C}_{4}{ }^{2+}$. These calculations failed since the calculated corrected values became unrealistically high. This indicates that the $\mathrm{Ti}^{2+}$ isotopes at 24.5 and $25 \mathrm{Da}$ overlap with other ions such as titanium hydrides. However, the two other $\mathrm{Ti}^{2+}$ isotopes at 23 and $23.5 \mathrm{Da}$ do not have any predicted overlaps and can thus be used for decomposition of the peak at $24 \mathrm{Da}$. Manual calculations showed a small overestimated value of $\mathrm{Ti}$ in the peak at $24 \mathrm{Da}$. The surplus amount $(0.87 \%$ with $0.6 \mathrm{~nJ})$ was instead assigned to $\mathrm{C}_{2}{ }^{+}$. This ion was reported to be field evaporated from other carbides by for example Thuvander et al. [12] as well as Liu and Andrén [17].

However, as a major peak the ${ }^{48} \mathrm{Ti}^{\mathrm{n}+}$ is expected to suffer, to some extent, from a loss due to the detector dead-time. Therefore, peak decomposition at $24 \mathrm{Da}$ according to the natural abundance of Ti will always yield too little ${ }^{12} \mathrm{C}_{2}^{+}$. To tackle this problem, the spectra of single and multiple events were studied closer, see figure 4 and 5 . Counts in the respective peaks of the single event spectra, $\left({ }^{46} \mathrm{Ti}^{2+}\right)_{\mathrm{s}},\left({ }^{47} \mathrm{Ti}^{2+}\right)_{\mathrm{s}}$ and $(24 \mathrm{Da})_{\mathrm{s}}$, were extracted and collected. These two isotopes were used because they are not affected by interference with other peaks. It was assumed that if the 24 Da peak had not suffered from missing ions due to dead-time issues of the detector, the multiple events should exhibit the same abundance distribution between these three peaks as the single events. Therefore, by using eq. (1), the amount of ions that should occur as multiple events at $24 \mathrm{Da}$ could be calculated and the corrected counts of multiple events at $24 \mathrm{Da}$ $(24 \mathrm{Da})_{\mathrm{c}-\mathrm{m}}$ were obtained. The difference between the corrected counts of multiple events and the recorded multiple counts gave an estimate of the amount of ions missed by the detector, as shown in eq. (2).

$$
\begin{aligned}
& (24 D a)_{c-m}=(24 D a)_{s} \times \frac{\left({ }^{46} T i^{2+}+{ }^{47} T i^{2+}\right)_{m}}{\left({ }^{46} T i^{2+}+{ }^{47} T i^{2+}\right)_{s}} \\
& { }^{12} C_{2 \text { Corr }}^{+}=(24 D a)_{c-m}-(24 D a)_{m}
\end{aligned}
$$

Since it was already shown that calculations based on the Ti isotopes ${ }^{46} \mathrm{Ti}^{2+}$ at $23 \mathrm{Da}$ and ${ }^{47} \mathrm{Ti}^{2+}$ at $23.5 \mathrm{Da}^{2}$ gave a slightly lower expected count than that recorded at $24 \mathrm{Da}$, the correction obtained by this calculation was dedicated to $\mathrm{C}_{2}^{+}$ions. In this calculation any contributions from $\mathrm{C}_{4}{ }^{2+}$ were neglected.The results after the correction at $24 \mathrm{Da}$ are shown in table 2. They are comparable with the results obtained by EELS, XRD and chemical analysis, as shown in table 3.

So far all the corrections were made on C. A similar effect as observed for ${ }^{12} \mathrm{C}$ is assumed to occur for ${ }^{14} \mathrm{~N}$ as well. However, since the abundance of the minor isotope of $\mathrm{N}$ is only $0.366 \%$, a similar correction as for $\mathrm{C}$ would introduce large uncertainties.

\subsubsection{Oxygen content quantification}

With APT analysis the problem with surface oxidation of Ti(C,N) was avoided because bulk material was analysed and the oxidised surface was field evaporated away. Observations regarding how $\mathrm{O}$ is detected with various laser energies were made. Oxygen evaporated as $\mathrm{TiO}$ with high laser energies and was for example preferably found as $\mathrm{TiO}^{2+}$ for a

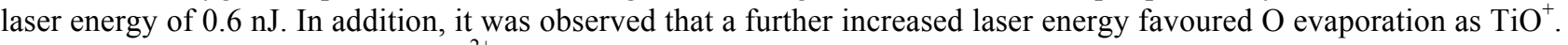
For a laser energy of $0.2 \mathrm{~nJ}$ no $\mathrm{TiO}^{2+}$ peaks were seen, as figure 7 , table 1 and 2 show. The $\mathrm{O}$ should consequently be found somewhere else in the mass spectrum, probably at $16 \mathrm{Da}$. Unfortunately ${ }^{16} \mathrm{O}^{+}$suffers from an overlap with ${ }^{48} \mathrm{Ti}^{3+}$. A correction similar to that applied to the $24 \mathrm{Da}$ peak was applied to the $16 \mathrm{Da}$ peak, but the result was inconclusive. This can perhaps be explained by the fact that there were only small amounts of $\mathrm{O}$ in the material and that there was a different relation between single and multiple events for ${ }^{48} \mathrm{Ti}^{3+}$ than for ${ }^{48} \mathrm{Ti}^{2+}$.

The $\mathrm{O}$ content was therefore obtained from a $0.6 \mathrm{~nJ}$ experiment and evaluated with decomposition calculations, because of the overlap with $\mathrm{TiN}^{2+}$ and $\mathrm{TiO}^{2+}$, see figure 7 . These observations suggest that analysis of small $\mathrm{O}$ contents in the $\mathrm{Ti}(\mathrm{C}, \mathrm{N})$ phase should preferably be performed using a relatively high laser energy so that the major part of $\mathrm{O}$ is field evaporated as $\mathrm{TiO}^{2+}$.

\subsubsection{APT compared to other techniques}

APT analysis with the applied corrections described in this paper, see table 3, showed good agreement with other techniques. The results obtained from the different techniques provided $\mathrm{C} / \mathrm{N}$ ratio values between 2.01 and 2.34 . This material probably contains some compositional variations that consequently will cause variations in the measured concentrations if single grains are considered. EELS encountered quantification problems because of surface oxidation. $\mathrm{XRD}$ did not provide any chemical information, only the $\mathrm{C} / \mathrm{N}$ ratio, and $\mathrm{O}$ was not considered. XRD as well as chemical analysis are macroscopic techniques giving average values from large volumes of the material and no local information is obtained. APT and EELS analysis, on the other hand, are performed on individual grains, which provide a local analysis - grain to grain. The advantage of using APT is that the bulk material is analysed, which excludes the influence of surface contamination and surface oxides. 


\section{Conclusions}

- Using a constant detection rate relations were observed between laser energy and the occurrence of atomic and molecular ions:

- More molecular ions occurred with increased laser energy.

- The molecules were also larger with increased laser energy (e.g. of the type $\mathrm{C}_{7}^{+}, \mathrm{C}_{5} \mathrm{~N}^{+}, \mathrm{C}_{2} \mathrm{~N}_{4}^{+}$and $\mathrm{CN}_{5}^{+}{ }^{+}$.

- The overall ratio between multiple and single events in the mass spectra decreased with increasing laser energy, but the variation was different for different peaks.

- A proposed quantification method was presented:

- first by applying an isotope correction for ${ }^{12} \mathrm{C}$ at 6 and $12 \mathrm{Da}\left({ }^{13} \mathrm{C}\right.$ correction)

- and then by a correction of the peak at $24 \mathrm{Da}\left(\mathrm{Ti}^{2+}\right.$ and $\mathrm{C}_{2}{ }^{+}$by ${ }^{12} \mathrm{C}_{2}^{+}$Corr correction) using single and multiple event spectra.

- After applied corrections, APT results provided satisfactory results that were comparable with results obtained from the other analysis techniques used (EELS, XRD and chemical analysis).

- $\quad$ Finally, the content of dissolved $\mathrm{O}$ in $\mathrm{Ti}(\mathrm{C}, \mathrm{N})$ was successfully quantified. It was found that $0.6 \mathrm{~nJ}$ was an optimum laser energy to use for quantitative determination of low $\mathrm{O}$ amounts because $\mathrm{O}$ appeared as $\mathrm{TiO}^{2+}$ (at $32 \mathrm{Da}$ ) instead of $\mathrm{O}^{+}$(at $\left.16 \mathrm{Da}\right)$ where the peak is suffering from overlap with $\mathrm{Ti}^{3+}$.

\section{Acknowledgements}

The authors would like to thank Dr Steven Webb at Diamond Innovation for sintering and supplying the material. The authors are also grateful to Dr Ernesto Coronel and Petra Orlander for their help with EELS acquisition as well as the Ångström Laboratory at Uppsala University for use of the TEM microscope, which was of great value for the investigation.

\section{References}

1. T.F. Kelly and M.K. Miller, Atom probe tomography Review of Scientific Instruments. 78 (2007) art. no. 031101

2. U. Rolander and H.-O. Andrén, On atom-probe analysis of cubic MX-type carbides and carbonitrides, Journal of Physics Colloque C6. 49 (1988) 299-304.

3. J. Zackrisson, M. Thuvander, P. Lindahl, and H.-O. Andrén, Atom probe analysis of carbonitride grains in (Ti, $\mathrm{W}, \mathrm{Ta}, \mathrm{Mo})(\mathrm{C}, \mathrm{N})(\mathrm{Co} / \mathrm{Ni})$ cermets with different carbon content, Applied Surface Science. 94/95 (1996) 351355.

4. U. Rolander and H.-O. Andrén. Atom-probe analysis applied to TiC-Ni-based cemented carbides. in Plansee, Paper HM 32a. 1989.

5. U. Rolander and H.-O. Andrén, Evaluation of atom-probe spectra from titanium carbonitride, Journal of Physics Colloque C8. 50 (1989) 529-532.

6. H.-O. Andrén, U. Rolander, and P. Lindahl, Phase composition in cemented carbides and cermets, International Journal of Refractory and Hard Metals. 12 (1993-1997) 107-113.

7. P. Lindahl, U. Rolander, and H.-O. Andrén, Atom-probe analysis of a commercial cermet, Surface Science. 246 (1991) 319-322.

8. P. Lindahl, U. Rolander, and H.-O. Andrén, High resolution microanalysis of titanium-based cermets, Journal of Hard Materials. 3 (1992) 259-267.

9. P. Lindahl, T. Mainert, H. Jonsson, and H.-O. Andrén, Microstructure and mechanical properties of a (Ti, W, Ta, Mo)(C, N) - (Co, Ni) type cermet, Journal of Hard Materials. 4 (1993) 187-204.

10. J. Angseryd, M. Elfwing, E. Olsson, and H.-O. Andrén, Detailed microstructure of a cBN based cutting tool, International Journal of Refractory Metals and Hard Materials. 27 (2009) 249-255

11. J. Angseryd, M. Albu, H.-O. Andrén, and G. Kothleitner, A quantitative analysis of a multi-phase polycrystalline cubic boron nitride tool material using DualEELS, Submitted to Micron.

12. M. Thuvander, J. Weidow, J. Angseryd, L.K.L. Falk, F. Liu, M. Sonestedt, K. Stiller, and H.-O. Andrén, Quantitative atom probe analysis of carbides, In this issue. (2010).

13. L. Yao, B. Gault, J.M. Cairney, and S.P. Ringer, On the multiplicity of field evaporation events in atom probe: A new dimension to the analysis of mass spectra Philosophical Magazine Letters. 90 (2010) 121-129.

14. M.K. Miller and K.F. Russell, Atom probe specimen preparation with a dual beam SEM/FIB miller, Ultramicroscopy. 107 (2007) 761-766.

15. D.R. Kingham, The post-ionization of field evaporated ions; a theoretical explanation of multiple charge states, Surf. Sci. 116 (1982) 273-301.

16. J.K. Böhlke, J.R. Leaeter, P. De Biévre, H. Hidaka, H.S. Peiser, K.J.R. Rosman, and P.D.P. Taylor, Isotopic compositions of the elements, 2001, J. Phys. Chem. Ref. Data. 34 (2001) 57-67.

17. F. Liu and H.-O. Andrén, Effects of laser pulsing on analysis of steels by atom probe tomography, In this issue. 
Tables

\begin{tabular}{|c|c|c|c|c|c|}
\hline Ion & $0.2 \mathrm{~nJ}$ & $0.6 \mathrm{~nJ}$ & Ion & $0.2 \mathrm{~nJ}$ & 0.6 nJ \\
\hline $\mathrm{C}^{2+}$ & $10.68 \%$ & $8.26 \%$ & $\mathrm{C}_{3}{ }^{+}$ & $0.70 \%$ & $1.74 \%$ \\
\hline $\mathrm{N}^{2+}$ & $1.24 \%$ & $1.34 \%$ & $\mathrm{C}_{2} \mathrm{~N}^{+}$ & $0.15 \%$ & $0.57 \%$ \\
\hline $\mathrm{C}^{+}$ & $10.14 \%$ & $5.29 \%$ & $\mathrm{CN}_{2}{ }^{+}$ & $0.03 \%$ & $0.13 \%$ \\
\hline $\mathrm{N}^{+}$ & $7.44 \%$ & $4.22 \%$ & $\mathrm{~N}_{3}^{+}$ & - & $0.25 \%$ \\
\hline $\mathrm{Ti}^{3+}$ & $15.89 \%$ & $8.00 \%$ & $\mathrm{C}_{4}{ }^{+}$ & $0.03 \%$ & $0.59 \%$ \\
\hline $\mathrm{C}_{3}^{2+}$ & $0.90 \%$ & $2.40 \%$ & $\mathrm{C}_{3} \mathrm{~N}^{+}$ & $0.02 \%$ & $0.15 \%$ \\
\hline $\mathrm{C}_{2} \mathrm{~N}^{2+}$ & $0.14 \%$ & $0.31 \%$ & $\mathrm{C}_{2} \mathrm{~N}_{2}^{+}$ & - & $0.06 \%$ \\
\hline $\mathrm{CN}_{2}{ }^{2+}$ & - & $0.08 \%$ & $\mathrm{C}_{5}^{+}$ & - & $0.11 \%$ \\
\hline $\mathrm{Ti}^{2+}$ & $40.01 \%$ & $48.65 \%$ & $\mathrm{TiN}^{+}$ & - & $0.49 \%$ \\
\hline $\mathrm{CN}^{+}$ & $1.75 \%$ & $0.98 \%$ & $\mathrm{TiO}^{+}$ & - & $0.50 \%$ \\
\hline $\mathrm{N}_{2}^{+}$ & $0.19 \%$ & $0.93 \%$ & $\mathrm{C}_{6}^{+}$ & - & $0.03 \%$ \\
\hline$* \mathrm{TiC}^{2+}$ & $2.46 \%$ & $3.39 \%$ & $\mathrm{C}_{5} \mathrm{~N}^{+}$ & - & $0.02 \%$ \\
\hline$* \mathrm{TiN}^{2+}$ & $7.94 \%$ & $9.03 \%$ & $\mathrm{C}_{2} \mathrm{~N}_{4}^{+}$ & - & $0.05 \%$ \\
\hline$* \mathrm{TiO}^{2+}$ & $0.11 \%$ & $1.78 \%$ & $\mathrm{CN}_{5}{ }^{+}$ & - & $0.02 \%$ \\
\hline $\mathrm{T}_{2} \mathrm{~N}^{2+}$ & - & $0.46 \%$ & $\mathrm{C}_{7}^{+}$ & - & $0.01 \%$ \\
\hline
\end{tabular}

Table 1. Concentration of different ions (in at \%) at laser energies of $0.2 \mathrm{~nJ}$ and $0.6 \mathrm{~nJ}$. (* indicates that there are major overlaps with neighbouring ions). 


\section{$0.2 \mathrm{~nJ}$}

Decomp. $\quad 56.86 \pm 0.05 \quad 26.23 \pm 0.04 \quad 16.83 \pm 0.03 \quad 0.07 \pm 0.002$
${ }^{13} \mathrm{C}_{\mathrm{Corr}}$
$54.5 \pm 1.4$
$29.3 \pm 2.0$
$16.1 \pm 0.4$
$0.07 \pm 0.004$
$24 \mathrm{Da}$
$52.8 \pm 1.5$
$31.5 \pm 2.2$
$15.6 \pm 0.5$
$0.07 \pm 0.004$

\section{6 nJ}

Decomp. $\quad 54.93 \pm 0.07 \quad 27.78 \pm 0.05 \quad 15.56 \pm 0.04 \quad 1.72 \pm 0.01$
${ }^{13} \mathrm{C}_{\text {Corr }}$
$52.9 \pm 0.9$
$30.5 \pm 1.4$
$15.0 \pm 0.3$
$1.66 \pm 0.03$
$24 \mathrm{Da}$
$50.6 \pm 1.1$
$33.5 \pm 1.7$
$14.3 \pm 0.4$
$1.58 \pm 0.04$

Table 2. Composition of the standard $\operatorname{Ti}(\mathrm{C}, \mathrm{N})$ material as given by the peak decomposition routine (Decomp.) in the IVAS software, with statistical uncertainties; after the ${ }^{13} \mathrm{C}$ correction $\left({ }^{13} \mathrm{C}_{\mathrm{Corr}}\right)$ with systematic and statistical uncertainties; and after the correction of the peak at $24 \mathrm{Da}$ (24Da) with systematic and statistical uncertainties. The systematic uncertainties for the ${ }^{13} \mathrm{C}$ correction originates from the uncertainty in natural abundance, $1.07 \pm 0.08 \%$, and the systematic errors in the correction of the peak at $24 \mathrm{Da}$ originate from the uncertainties in the data processing when manually summing up the counts, with the additional uncertainties in the ${ }^{13} \mathrm{C}$ correction included.

\begin{tabular}{ccccccc} 
& Nominal & $\begin{array}{c}\text { EELS } \\
\text { [at\%] }\end{array}$ & XRD & $\begin{array}{c}\text { Chemical } \\
\text { analysis [at\%] }\end{array}$ & $\begin{array}{c}\text { Atom probe Atom probe } \\
\text { 0.2nJ [at\%] }\end{array}$ & $\begin{array}{c}\text { 0.6nJ [at\%] } \\
\text { [at\% }\end{array}$ \\
\hline $\mathbf{C}$ & 35 & 33.4 & - & 33.1 & $31.5 \pm 2.2$ & $33.5 \pm 1.7$ \\
$\mathbf{N}$ & 15 & 15.1 & - & 15.9 & $15.6 \pm 0.5$ & $14.3 \pm 0.4$ \\
$\mathbf{C} / \mathbf{N}$ & 2.33 & 2.21 & 2.23 & 2.08 & 2.01 & 2.34 \\
$\mathbf{O}$ & - & - & - & 1.16 & 0.07 & 1.58
\end{tabular}

Table 3. Comparison of APT analyses with results from EELS, XRD and chemical analysis. 


\section{Figures}

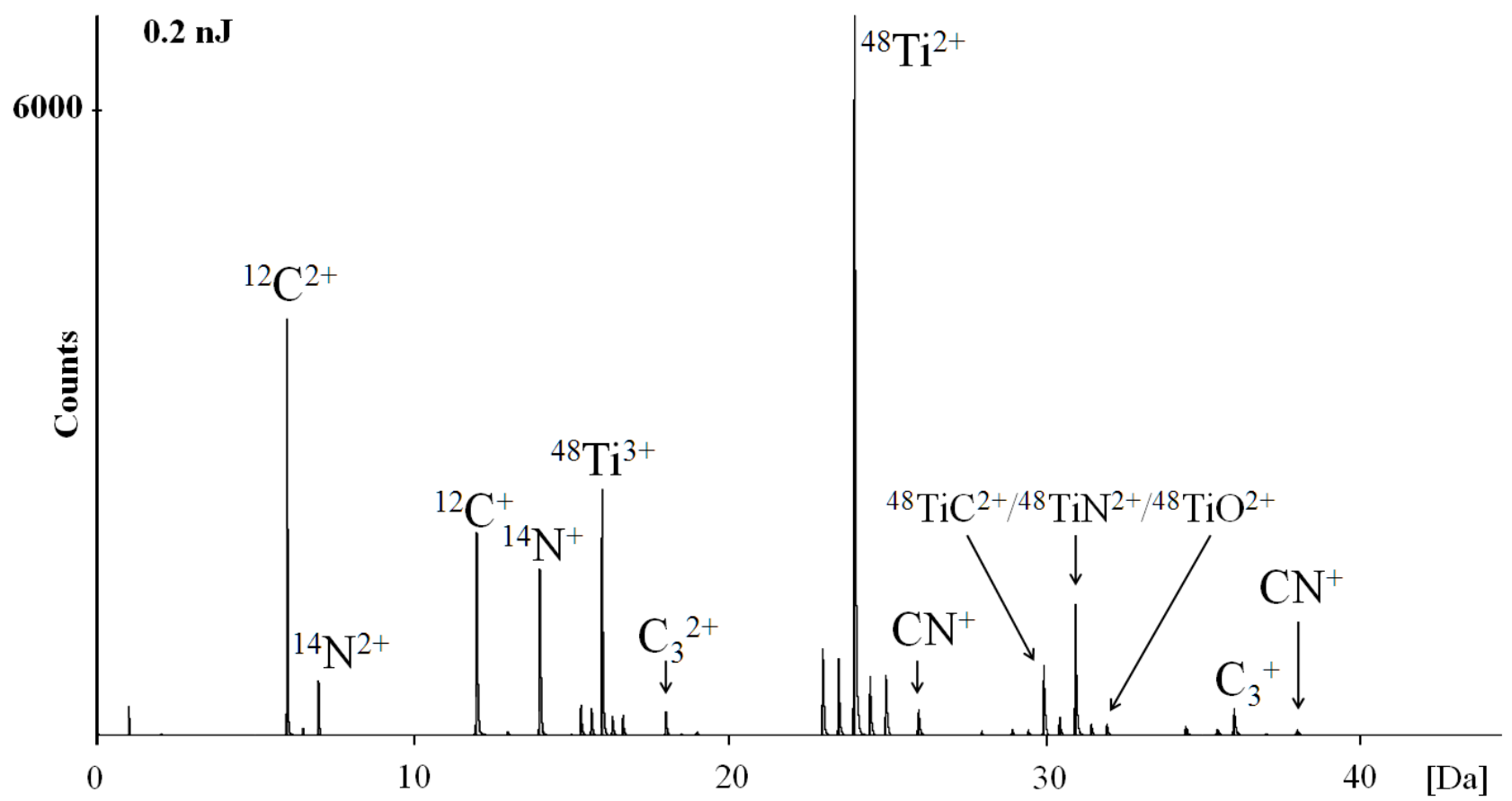

Figure 1. A complete mass spectrum from the analysis with $0.2 \mathrm{~nJ}$ applied laser energy.

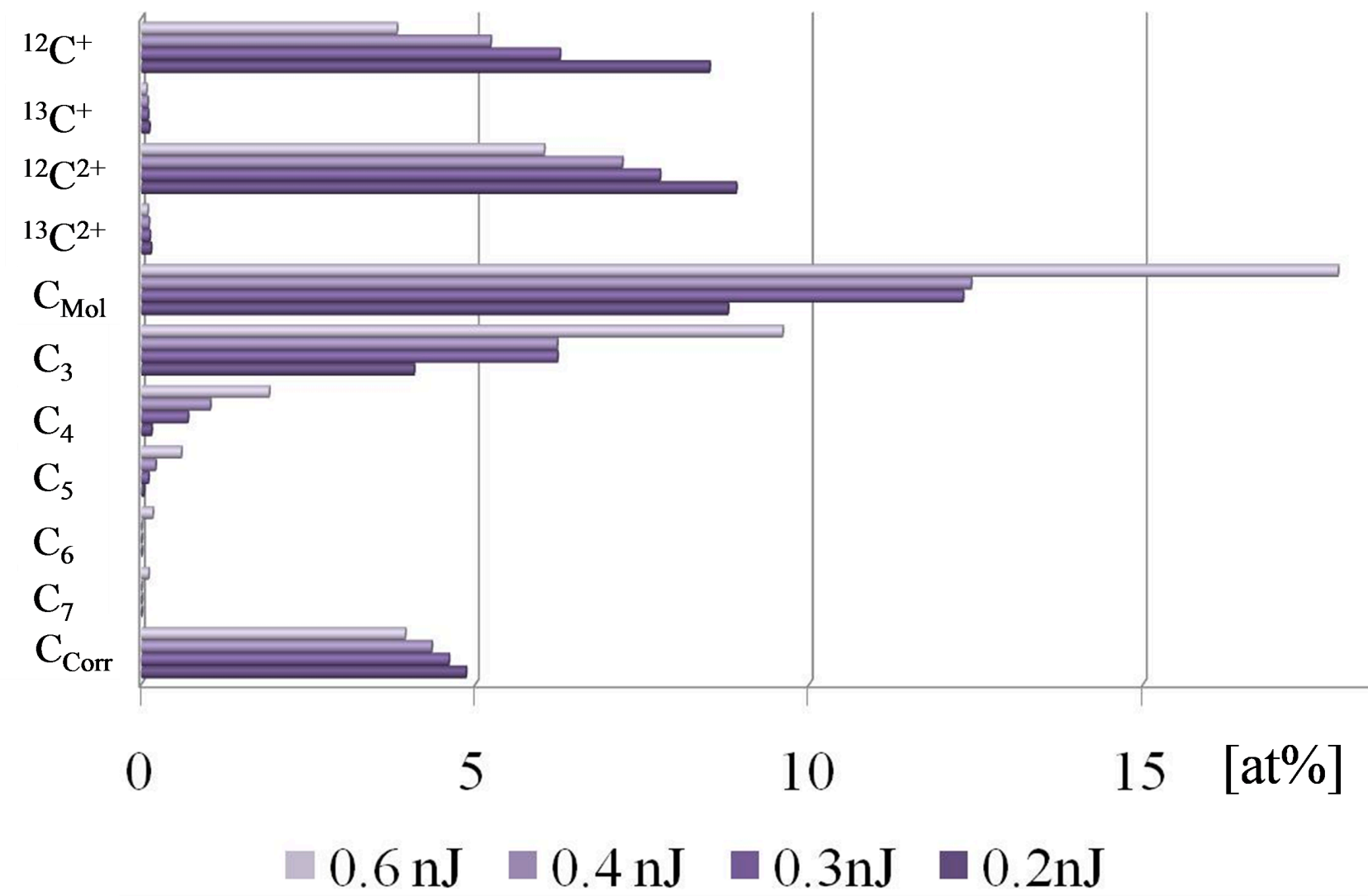

Figure 2. The occurrence of $\mathrm{C}$ as atomic ions and $\mathrm{C}$ in molecular ions, $\mathrm{C}_{\mathrm{Mol}}$, as a function of laser energy. $\mathrm{C}_{\mathrm{Mol}}$ increases with laser energy. In addition, the occurrence of $\mathrm{C}_{3}\left(\mathrm{C}_{3}{ }^{+}\right.$and $\left.\mathrm{C}_{3}{ }^{2+}\right), \mathrm{C}_{4}{ }^{+}, \mathrm{C}_{5}{ }^{+}, \mathrm{C}_{6}{ }^{+}$and $\mathrm{C}_{7}{ }^{+}$is shown. The corrected $\mathrm{C}$ value $\left(\mathrm{C}_{\text {corr }}\right)$ discussed in section 4.3.1, decreases with increasing laser energy. 


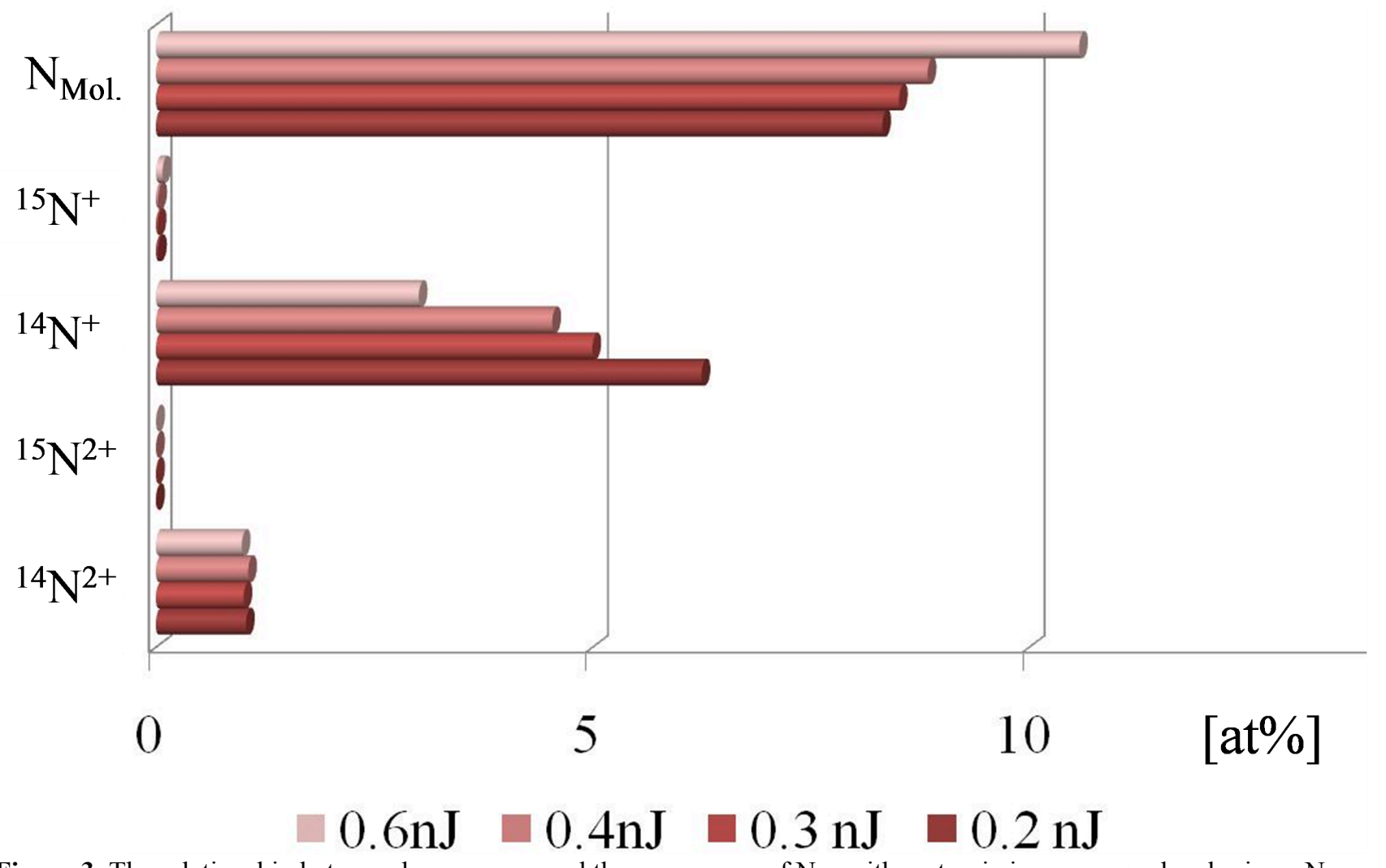

Figure 3. The relationship between laser energy and the occurrence of $\mathrm{N}$ as either atomic ions or as molecular ions, $\mathrm{N}_{\mathrm{Mol}}$.

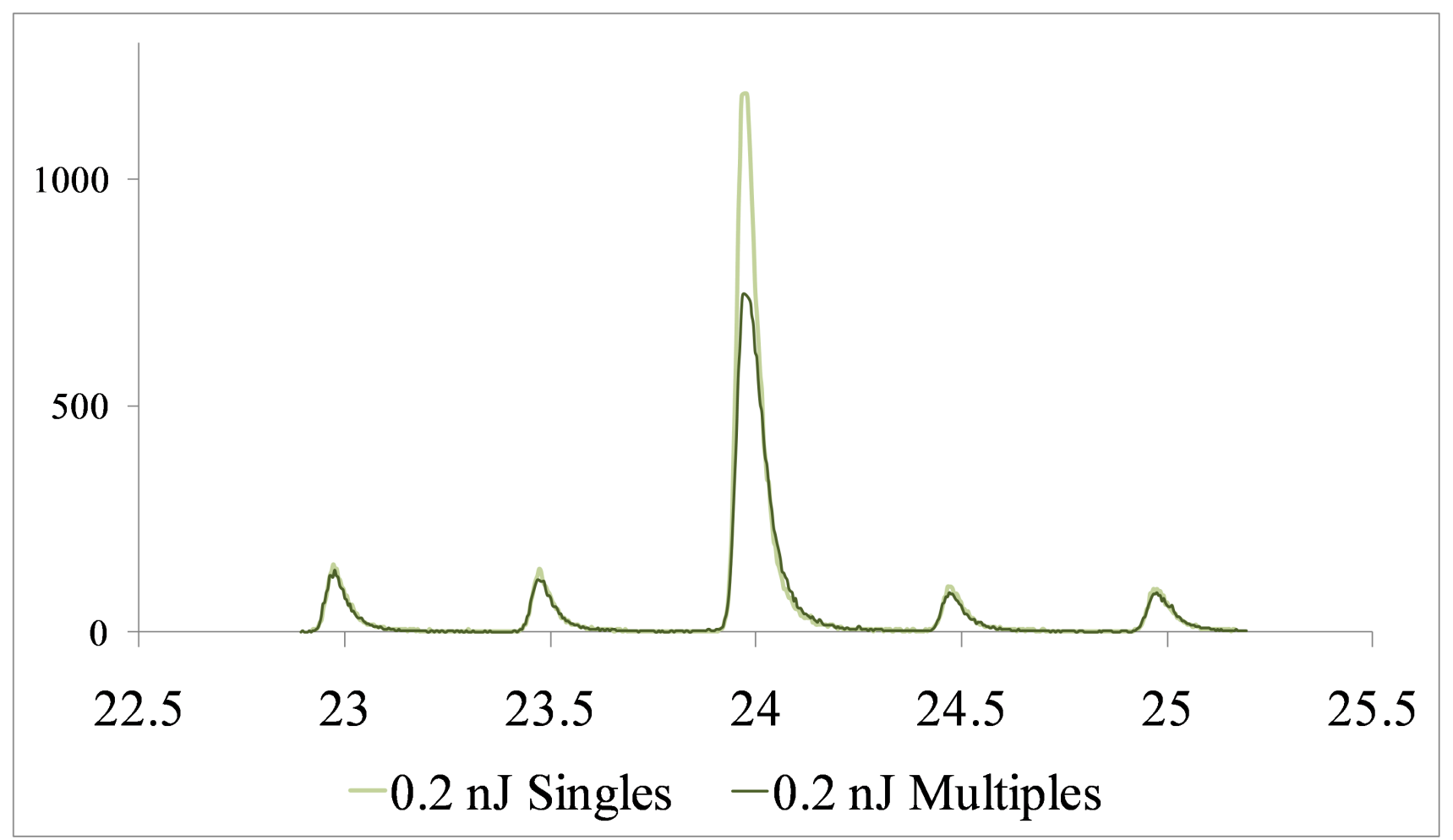

Figure 4. The peak at $24 \mathrm{Da}$ separated into single and multiple events at $0.2 \mathrm{~nJ}$. The light color graph represents the single events and the dark color graph (lower) represents multiple events. 


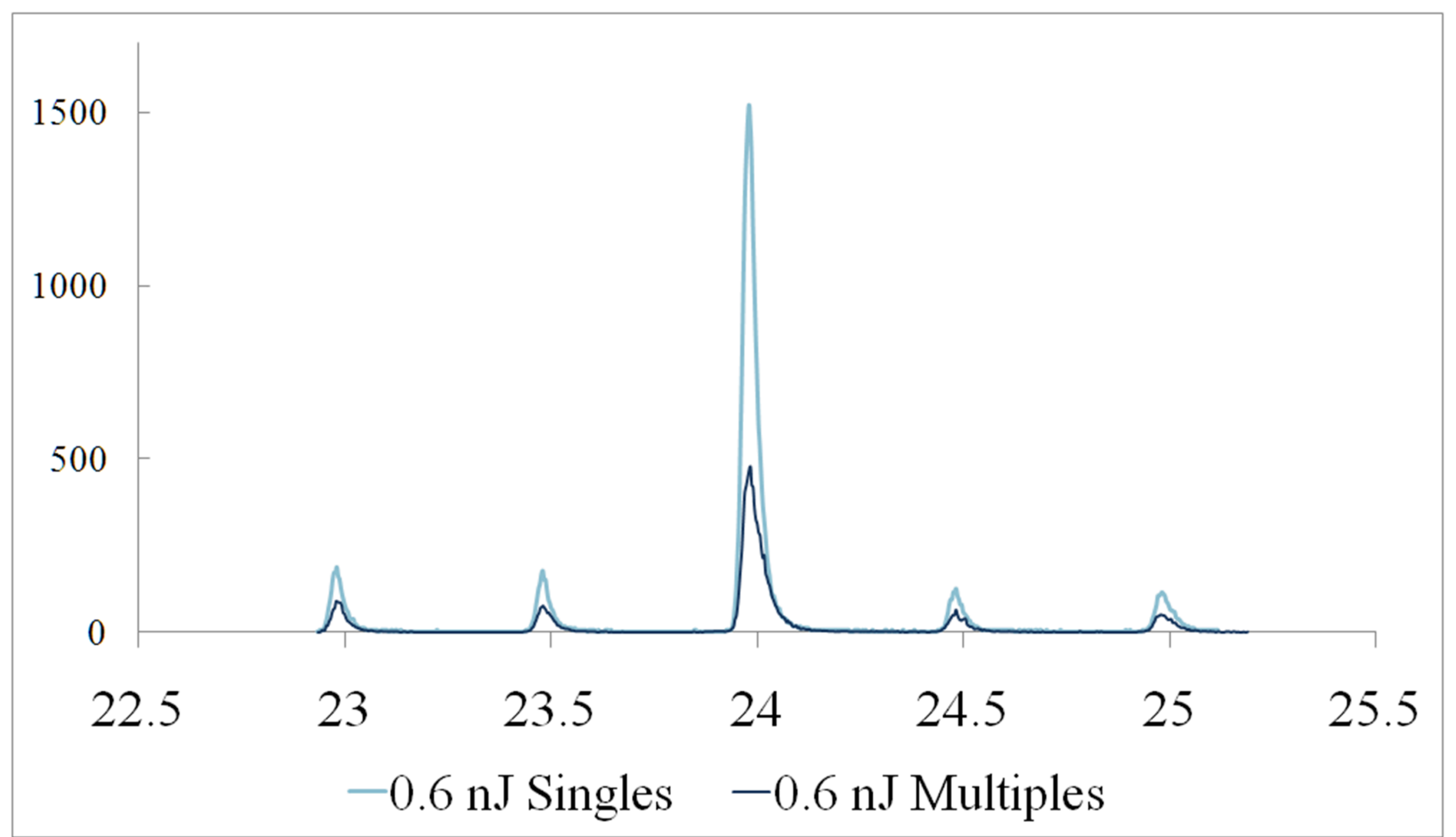

Figure 5. The peak at $24 \mathrm{Da}$ separated into single and multiple events at $0.6 \mathrm{~nJ}$. The light color graph represents the single events and the dark color graph (lower) represents multiple events.

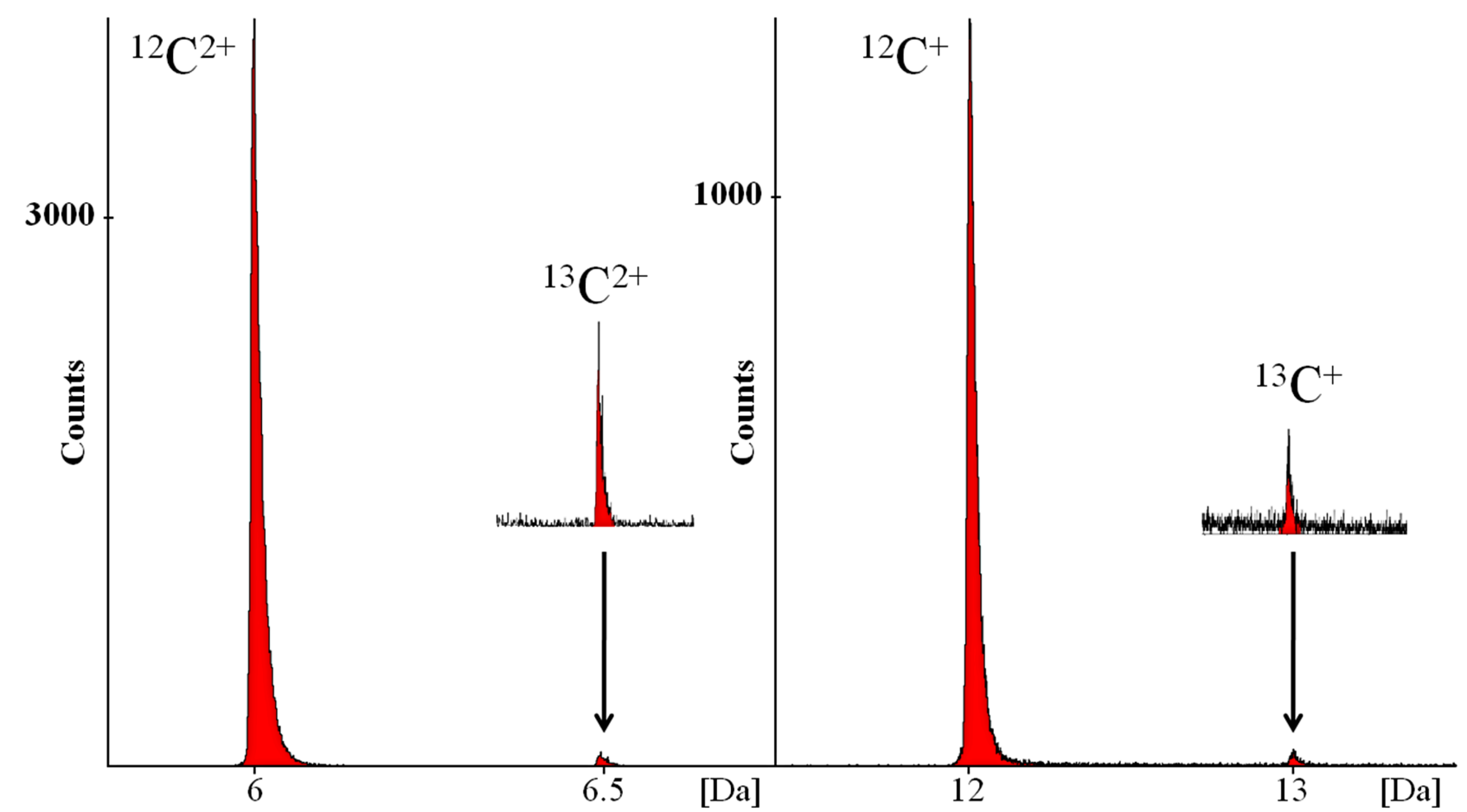

Figure 6. A close-up of the mass spectrum for the main carbon peaks $\mathrm{C}^{2+}$ and $\mathrm{C}^{+}$at $6,6.5,12$ and $13 \mathrm{Da}$ (linear scale). 


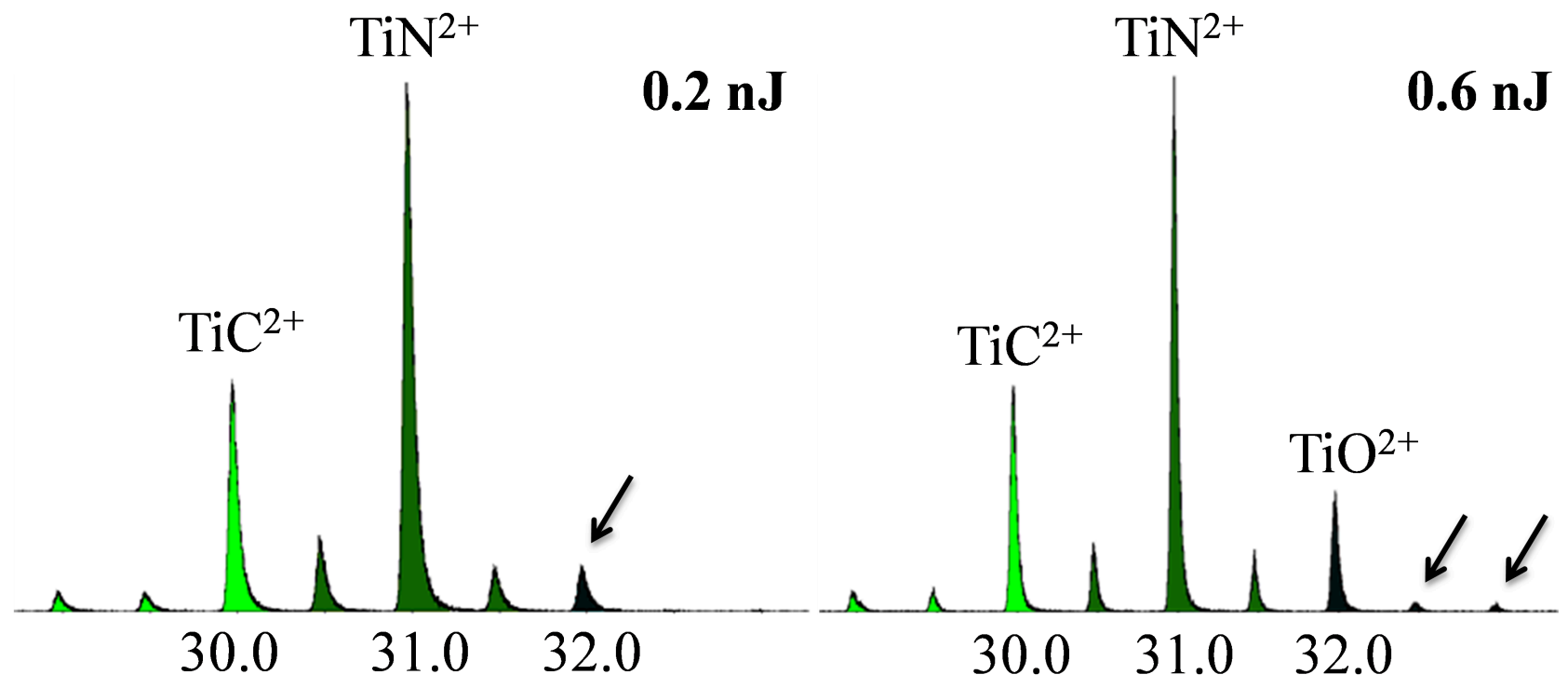

Figure 7. Mass spectra in the $30-32 \mathrm{Da}$ interval where $\mathrm{TiC}^{2+}, \mathrm{TiN}^{2+}$ and $\mathrm{TiO}^{2+}$ partly overlap. The arrows indicate the position of the absent ${ }^{48} \mathrm{TiO}^{2+}$ peak in the mass spectrum obtained using $0.2 \mathrm{~nJ}$ and the present ${ }^{49} \mathrm{TiO}^{2+}$ and ${ }^{50} \mathrm{TiO}^{2+}$ peaks in the mass spectrum obtained using $0.6 \mathrm{~nJ}$. 